\title{
The Effect of Trace Elements Accumulation on the Levels of Secondary Metabolites and Antioxidant Activity in Carrots, Onions and Potatoes
}

\author{
Evangelia Flemotomou, Theofanis Molyviatis, Ioannis Zabetakis \\ Laboratory of Food Chemistry, Faculty of Chemistry, School of Sciences, National and Kapodistrian University of Athens, Athens, \\ Greece. \\ Email: izabet@chem.uoa.gr
}

Received September $2^{\text {nd }}, 2011$; revised October $2^{\text {nd }}, 2011$; accepted October $10^{\text {th }}, 2011$.

\begin{abstract}
The objective of this work is to correlate the accumulation of trace elements in food tubers with possible alterations of the secondary plant metabolism. Samples of carrots, onions and potatoes grown in the environmentally polluted area of Asopos river in Viotia, Greece and other Greek areas (control) were analyzed for carotenoids by HPLC-UV and DPPH antioxidant activity. In carrots, the levels of $\alpha$-carotene, $\beta$-carotene and lutein were quantified and it was found that Asopos samples had statistically significantly lower levels of $\beta$-carotene compared to control ones. Also, in potatoes, the levels of lutein in Asopos samples were statistically significantly lower than control ones. However, in onions, the levels of lutein between Asopos and control samples were not found statistically different. In all samples, no statistically significant differences in the levels of DPPH activity (measured as $I C_{50}$ : sample levels that cause 50\% inhibition of DPPH scavenging activity) were observed. In conclusion, the presence of heavy metals in carrots and potatoes has affected the levels of carotenoids.
\end{abstract}

Keywords: Asopos, Carotenoids, Tuber Foods, Nickel, Chromium, DPPH

\section{Introduction}

The cross-contamination of human food chain by risk elements [1] is one of the most important problems that today's food chemists need to address given the high impact of contaminated crops (e.g. carrots, onions and potatoes) which are basic components of our diet. The reasons of heavy metal accumulation are mainly anthropogenic: fertilizers, mining and industrial processing [2].

Food cross-contamination by heavy metals has been widely studied [1,3] since these risk elements do not only affect the nutritional value of food, but also have detrimental effects on consumers' health. With regard to the levels of heavy metals in food, the current trend is that national and international regulations on food safety are getting stricter by lowering the maximum permissible levels of toxic metals. For the case of $\mathrm{Cd}$, according to the latest opinion of EFSA [4] a lower Provisional Tolerable Weekly Intake (PTWI) is suggested. On the contrary, continuously increasing levels of risk elements in food grown in polluted areas worldwide are being reported [5]; the levels of trace elements were quantified in food grown in Asopos region, where the underground water table has been extensively contaminated. These two trends are somehow contradicting and they need to be taken into consideration by policy making and legislative bodies to maximize the "protection net" to Public Health.

In the case of Asopos river in Greece, this river was designated as an industrial zone in 1969 and 10 years later, municipalities took the decision to allow treated waste to be dumped into its waters. These facts have resulted in the extreme pollution not only of Asopos but also of the groundwater of the surrounding area. Despite its heavy pollution, this area is widely used for agricultural production.

Plants grown in contaminated soils tend to accumulate heavy metals, which cause changes to their normal metabolic functions [6,7]. A correlation between heavy metals and free radicals production has been indicated [8].

In recent years, there has been an increase of interest in the carotenoid role in human nutrition [9]. Apart from their use as natural pigments in food industry, carote- 
noids are well known for their antioxidant activity and their protective role against human diseases [10,11], such as some types of cancer, UV-induced skin damage, coronary heart disease, cataract and macular degeneration [12]. Carotenoids are products of secondary metabolism of plants and are synthesized and localized in the plastids of plant cells [13]. External factors may interfere and affect their physiological function. Heavy metals, which are known for their ability to replace the soil's essential metals, are one of these factors [14].

In the present study, the food produced in this area was evaluated by comparing it with food produced in nonpolluted areas (control). In our previous study [5], high levels of nickel and chromium were found in carrots, onions and potatoes from Asopos region as opposed to control ones. In this paper, the effect of heavy metals on the secondary metabolism of plants (i.e. levels of carotenoids and total antioxidant activity) is studied in carrots (Daucus carota L.), potatoes (Solanum tuberosum L.) and onions (Allium cepa $\mathrm{L}$.).

\section{Materials and Methods}

\subsection{High Performance Liquid Chromatography (HPLC) Assay}

\subsubsection{Samples}

Commercially available samples originating from the Asopos region in Viotia, Greece which is located $40 \mathrm{~km}$ north west of Athens (Asopos samples) were obtained from super markets in Athens, Greece. These Asopos samples were appropriately coded $\left(\mathrm{S}_{\mathrm{i}}, \mathrm{i}=1-8\right)$ as opposed to control samples (Control) whose origin is from other areas of Greece, Italy and Cyprus where no known water and soil pollution exists. Control samples were sourced as follows: carrots from Greece and Italy; onions from Greece and Cyprus; potatoes from Greece and $\mathrm{Cy}-$ prus.

\subsubsection{Chemicals}

All chemicals and solvents were purchased from Merck, Germany apart from lutein which was purchased from Extrasynthese, France and $\alpha$-carotene and $\beta$-carotene which were purchased from Fluka, UK.

\subsubsection{Sample Preparation}

All food samples were frozen with liquid nitrogen after having been peeled and carved. Then, they were ground to obtain a fine powder using a cyclone mixer mill (thermomix 3300, Vorwerk, Paris, France) and then kept at $-15^{\circ} \mathrm{C}$ before extraction. The extraction of carotenoids was carried out as described by Wrolastrad et al. [15] with slight modifications. In detail, carotenoids were released from the powdered samples $(20 \mathrm{~g})$ by adding $2 \mathrm{~g}$ of magnesium carbonate and $25 \mathrm{~mL}$ of 50:50 methanol: tetrahydrofuran (THF). The crude suspensions were centrifuged at $6000 \times \mathrm{g}$ at $4^{\circ} \mathrm{C}$ for $10 \mathrm{~min}$ (Sorvall RC-5B Refrigerated Superspeed Centrifuge, Du Pont Instruments). The procedure was repeated until the extracting solvent was colourless and the extract was vacuum-filtered. The filtrates were then concentrated using a rotary evaporator apparatus (Heidolph Laborota $4000 \mathrm{eco} / \mathrm{WB} /$ G1) and transferred to a $25 \mathrm{~mL}$ volumetric flask, while carrot extracts were diluted to a known volume with reagent alcohol so that THF levels were less than $10 \%$ of the total solution. Due to high lipid and low carotenoid content of onion samples, saponification (alkaline hydrolysis) was carried out as follows: $5 \mathrm{~mL}$ of the concentrated sample were transferred in a $50 \mathrm{~mL}$ capped tube. One $\mathrm{mL}$ of $10 \%(\mathrm{w} / \mathrm{v})$ pyrogallol in reagent alcohol and $2 \mathrm{~mL}$ of $40 \%$ (w/v) KOH in methanol were added. The tube was flushed with nitrogen gas and then capped. The sample was saponified for $30 \mathrm{~min}$ in an ultrasonic bath (Elmasonic S15H). After saponification, the sample was diluted with $8 \mathrm{~mL}$ of saturated $\mathrm{NaCl}$ solution and then 10 $\mathrm{mL}$ of 75:25 hexane/THF was added. After vigorous mixing, the upper phase, which contains the carotenoids, was removed. The last step was repeated until the upper phase was colourless. The collected solution was concentrated using a rotary evaporator apparatus. Before the injection into the HPLC analysis system, all samples were filtered through a $0.45 \mu \mathrm{m}$ filter. All analyses were carried in triplicates.

\subsubsection{Preparation of Calibration Curves}

Five $\mathrm{mg}$ of lutein were dissolved in $100 \mathrm{~mL}$ reagent alcohol containing $30 \mathrm{ppm}$ butylated hydroxytoluene (BHT), while $5 \mathrm{mg}$ of $\alpha$-carotene and $\beta$-carotene were dissolved in $10 \mathrm{~mL}$ THF $(1 \mathrm{~L}$ of THF was previously stabilized with $250 \mathrm{~mL}$ BHT) and then diluted to $100 \mathrm{~mL}$ with reagent alcohol. Full standard curves were constructed with five different concentrations for each carotenoid. All analyses of standard solutions were carried out in triplicate. The concentrations for the lutein standards ranged from 0.01 to $0.16 \mathrm{mg} \cdot \mathrm{L}^{-1}$, while the $\alpha$ - and $\beta$-carotene concentrations ranged from 0.5 to $10.0 \mathrm{mg} \cdot \mathrm{L}^{-1}$, according to Muller [16].

The calibration curves obtained (y being the peak area, $\mathrm{x}$ being the concentration of the standard compound in $\mathrm{mg} \cdot \mathrm{L}^{-1}$ ) were $\mathrm{y}=1236560.31 \mathrm{x}+3574.21$ with $\mathrm{R}^{2}=$ 0.9999 for lutein, $\mathrm{y}=1545475.41 \mathrm{x}-164262.12$ with $\mathrm{R}^{2}$ $=0.9984$ for $\alpha$-carotene and $\mathrm{y}=1559668.43 \mathrm{x}-$ 165770.72 with $\mathrm{R}^{2}=0.9986$ for $\beta$-carotene.

\subsubsection{HPLC Analysis}

The HPLC apparatus consisted of an Agilent SERIES 1100 , equipped with a Variable Wavelength UV-Vis de- 
tector and an intergrator Agilent 3395. A $50 \mu \mathrm{L}$ loop was used. All solvents were of HPLC grade purity. The mobile phase was a binary mixture of methanol: acetonitrile $(85: 15, \mathrm{v} / \mathrm{v})$. The column was a C18 Zorbax SB $(4.6 \times$ $250 \mathrm{~mm}, 5 \mu \mathrm{m})$. The column was kept at room temperature $\left(20^{\circ} \mathrm{C}\right)$ and the flow rate was $1.5 \mathrm{~mL} \cdot \mathrm{min}^{-1}$. The detection wavelength was $450 \mathrm{~nm}$.

\subsection{Diphenylpicrylhydrazyl (DPPH) Antioxidant Activity Assay}

Antioxidant activities were measured using the method of Molyneux [17]. In brief, antioxidant compounds were extracted from the powdered and freezed samples $(10 \mathrm{~g})$ by adding $50 \mathrm{~mL}$ methanol in an erlenmeyer flask. The mixture was transferred into an ultrasonic bath (Elmasonic $\mathrm{S} 15 \mathrm{H}$ ) for $30 \mathrm{~min}$. The extract was vacuum filtered, concentrated to $1 \mathrm{~mL}$, transferred into a UV-Vis protecting vial and finally dried under nitrogen. All samples were then kept at $-80^{\circ} \mathrm{C}$ for 24 hours and then lyophilized in a freeze-dryer (Heto LyoLab 3000). Diphenylpicrylhydrazyl (DPPH) $(12.5 \mathrm{mg}$ ) was diluted in $100 \mathrm{~mL}$ of reagent alcohol, in order to prepare a stock solution of final concentration $317 \mu \mathrm{M}$. Spectroscopic cuvettes of optical diameter $1 \mathrm{~cm}$ and total volume of $1 \mathrm{~mL}$ were used. The dried extract was dissolved in a mixture of ethanol: water (70:30). The precise concentration of the extract solution was experimentally determined by constructing an inhibition curve for each sample as follows: the volume of the DPPH solution ( $300 \mu \mathrm{l})$ was adjusted to $1 \mathrm{ml}$ in the first cuvette by adding ethanol, in order to give absorbance values less than 1.0. The rest of the cuvettes were filled with the DPPH solution $(300 \mu \mathrm{l})$ and the extract solution, gradually dissolving it with ethanol so as to give different sample concentrations in each cuvette. In total, four different concentrations for every sample were measured. The cuvettes were then placed in a water bath for $30 \mathrm{~min}$ at $30^{\circ} \mathrm{C}$ and then spectroscopicaly measured at $517 \mathrm{~nm}$ using an Helios $\beta$ spectrophotometer. The \% inhibition of DPPH was calculated from the absorbance readings using the equation: $\% I=100\left(A_{0}\right.$ $\left.-A_{c}\right) / A_{0}$, where $A_{0}$ is the absorbance value of the blank (DPPH solution) and $A_{c}$ is the absorbance value of the sample (DPPH and extract solution).

The $\%$ inhibition was plotted against samples concentrations giving the inhibition curve. The linear region of this curve was used to calculate the concentration of the sample which caused 50\% inhibition of DPPH scavenging activity. All analyses were carried in triplicates. A separate calibration curve was obtained for each sample, a typical calibration curve was (y being the \% inhibition of DPPH, $x$ being the sample concentration in $\left.\mathrm{mg} \cdot \mathrm{L}^{-1}\right): y$ $=36.72 \mathrm{x}+6.21$ with $\mathrm{R}^{2}=0.9986$.

\subsection{Statistical Analysis}

All HPLC and enzymatic analyses were carried out in triplicates. Experimental HPLC and DPPH data were analyzed using F-test and the Student test analysis (Ttest). Before the T-test analysis, an F-test analysis was performed to examine if there was significant difference between the variances of Asopos and control samples. Both tests were performed using the Microsoft Excel 2010 statistical program, with a level of confidence of $95 \%$.

\section{Results and Discussion}

\subsection{HPLC Analysis of Carotenoids}

The $\beta$-carotene content in carrots varied significantly between Asopos and control samples $(p=0.039)$, while lutein $(p=0.36)$ and $\alpha$-carotene $(p=0.76)$ contents showed no statistically significant difference. The mean carotenoid levels for Asopos samples were $77.13 \mathrm{mg} \cdot \mathrm{kg}^{-1}$ for $\beta$-carotene, $5.68 \mathrm{mg} \cdot \mathrm{kg}^{-1}$ for lutein and $39.47 \mathrm{mg} \cdot \mathrm{kg}^{-1}$ for $\alpha$-carotene, whereas for control samples were 89.30 $\mathrm{mg} \cdot \mathrm{kg}^{-1}, 4.07 \mathrm{mg} \cdot \mathrm{kg}^{-1}$ and $37.59 \mathrm{mg} \cdot \mathrm{kg}^{-1}$, respectively (Table 1).

The lutein content in potatoes was $143.33 \mathrm{mg} / \mathrm{kg}$ for Asopos samples and $286.99 \mathrm{mg} / \mathrm{kg}$ for control samples. Statistical analysis showed significant difference between them $(p=0.01)$ (Table 2).

Concerning onions, lutein concentration was found $23.38 \mathrm{mg} / \mathrm{kg}$ in Asopos bulbs and $18.96 \mathrm{mg} / \mathrm{kg}$ in control ones while statistical analysis showed no significant difference between them $(p=0.64)$ (Table 3).

These data suggest that heavy metals may affect the biosynthesis of carotenoids (lutein and $\beta$-carotene in this case). This correlation between heavy metal uptake and plant metabolic changes has been studied in the past from different angles. Chromium toxicity can provoke three types of metabolic disturbances: 1) alterations in pigment production, 2) increased metabolite production (ascorbic acid, glutathione) and 3) production of new metabolites which make the plant tolerant against chromium toxicity [6]. Although the structure of plant root tissues is capable of filtering or rejecting an amount of heavy metals, higher concentrations of heavy metals in the soil are related to toxic effects [18]. The effect of nickel was also studied in potato cultivars and it was found that nickel suppressed growth and decreased iron levels [19]; according to these authors, nickel can substitute iron in the plant. Regarding carrots, it has been shown that cadmium in combination with zinc can decrease the levels of ascorbic acid, total phenolics, carotenoids and chlorophyll [20]. Additionally, chromium was found to cause suspension in the uptake of many essentials metals and 
Table 1. Content of carotenoids and $\mathrm{IC}_{30}$ values in carrot samples ${ }^{a}$.

\begin{tabular}{|c|c|c|c|c|}
\hline \multirow[b]{2}{*}{ Asopos samples } & \multicolumn{3}{|c|}{ Carotenoids concentration (mg kg ${ }^{-1}$ edible portion) } & \multirow[t]{2}{*}{$\begin{array}{l}\mathrm{IC}_{30}\left(\mathrm{mg} \cdot \mathrm{mL}^{-1}\right. \\
\text { sample solution) }\end{array}$} \\
\hline & Lutein & $\alpha$-carotene & $\beta$-carotene & \\
\hline $\mathrm{S}_{1}$ & $5.66 \pm 0.09$ & $51.73 \pm 3.62$ & $88.16 \pm 3.49$ & $1.64 \pm 0.082$ \\
\hline $\mathrm{S}_{2}$ & $3.41 \pm 0.01$ & $40.78 \pm 1.86$ & $77.34 \pm 2.44$ & $2.63 \pm 0.132$ \\
\hline $\mathrm{S}_{3}$ & $3.99 \pm 0.08$ & $33.94 \pm 0.14$ & $71.92 \pm 0.54$ & $4.09 \pm 0.205$ \\
\hline $\mathrm{S}_{4}$ & $4.96 \pm 0.23$ & $35.79 \pm 0.34$ & $69.77 \pm 1.57$ & $3.23 \pm 0.162$ \\
\hline $\mathrm{S}_{5}$ & $4.36 \pm 0.09$ & $34.99 \pm 0.57$ & $67.58 \pm 0.26$ & $2.07 \pm 0.010$ \\
\hline $\mathrm{S}_{6}$ & $6.07 \pm 2.67$ & $41.48 \pm 1.21$ & $85.76 \pm 0.22$ & $4.71 \pm 0.235$ \\
\hline $\mathrm{S}_{7}$ & $11.30 \pm 3.18$ & $37.59 \pm 1.76$ & $79.36 \pm 1.91$ & $2.28 \pm 0.011$ \\
\hline Mean & $5.68 \pm 0.91$ & $39.47 \pm 1.36$ & $77.13 \pm 1.49$ & $2.95 \pm 0.119$ \\
\hline \multicolumn{5}{|l|}{ Control samples } \\
\hline $\mathrm{C}_{1}$ & $2.50 \pm 0.06$ & $33.38 \pm 4.56$ & $84.60 \pm 2.70$ & $2.34 \pm 0.012$ \\
\hline $\mathrm{C}_{2}$ & $4.45 \pm 0.27$ & $49.04 \pm 2.61$ & $93.49 \pm 8.33$ & $2.99 \pm 0.150$ \\
\hline $\mathrm{C}_{3}$ & $5.25 \pm 0.04$ & $30.34 \pm 7.25$ & $89.81 \pm 2.03$ & $2.51 \pm 0.126$ \\
\hline Mean & $4.07 \pm 0.12$ & $37.59 \pm 4.81$ & $89.30 \pm 4.35$ & $2.61 \pm 0.096$ \\
\hline$p$ values (F-Test) & 0.478 & 0.312 & 0.525 & 0.17 \\
\hline$p$ values (T-Test) & 0.359 & 0.762 & 0.039 & 0.63 \\
\hline
\end{tabular}

${ }^{a}$ Each value is the mean of three replicates \pm standard deviation (95\% confidence levels). ${ }^{\mathrm{b}}$ In carrots, due to matrix problems, it was not feasible to calculate the $\mathrm{IC}_{50}$ value but the $\mathrm{IC}_{30}$ one.

Table 2. Content of lutein and $\mathrm{IC}_{50}$ values in potato samples $^{\alpha}$.

\begin{tabular}{|c|c|c|}
\hline & $\begin{array}{c}\text { Lutein concentration } \\
\left(\mathrm{mg} \cdot \mathrm{kg}^{-1} \text { edible portion) }\right.\end{array}$ & $\mathrm{IC}_{50} \underset{\text { solution) }}{\left(\mathrm{mg} \cdot \mathrm{ml}^{-1} \text { sample }\right.}$ \\
\hline \multicolumn{3}{|l|}{ Asopos samples } \\
\hline $\mathrm{S}_{1}$ & $135.53 \pm 5.60$ & $0.67 \pm 0.034$ \\
\hline $\mathrm{S}_{2}$ & $142.47 \pm 2.32$ & $0.46 \pm 0.023$ \\
\hline $\mathrm{S}_{3}$ & $151.99 \pm 3.36$ & $0.65 \pm 0.033$ \\
\hline Mean & $143.33 \pm 3.76$ & $0.59 \pm 0.030$ \\
\hline \multicolumn{3}{|l|}{ Control samples } \\
\hline $\mathrm{C}_{1}$ & $320.27 \pm 3.28$ & $1.19 \pm 0.060$ \\
\hline $\mathrm{C}_{2}$ & $253.70 \pm 2.03$ & $0.38 \pm 0.019$ \\
\hline Mean & $286.99 \pm 2.66$ & $0.79 \pm 0.040$ \\
\hline$p$ values (F-Test) & 0.06 & 0.08 \\
\hline$p$ values (T-Test) & 0.01 & 0.59 \\
\hline
\end{tabular}

${ }^{\alpha}$ Each value is the mean of three replicates \pm standard deviation $(95 \%$ confidence levels). trace elements, such as iron, phosphorus, potassium, nitrogen, copper, molybdenum and zinc, depending on the plant's organ and the level of chromium in the soil [21]. Hexavalent chromium [Cr (VI)] functions as an oxidizing agent and forms free radicals when it is reduced to $\mathrm{Cr}$ (III) inside the plant cell which in turn generates reactive oxygen species (ROS). Cr (III) can also cause toxic effects due to its ability to coordinate various organic compounds resulting in inhibition of some metallo-enzyme systems [6].

Evaluating our results on Asopos and control samples, an effect of heavy metals in carotenoid metabolic pathway could be suggested. Specifically, Asopos carrot samples showed a decrease in $\beta$-carotene concentration, while contaminated potato samples showed decrease in lutein concentration in comparison with control samples. However, lutein in onion and carrot samples, as well as $\alpha$-carotene in carrot samples did not show any statistically significant difference. The explanation of why only the levels $\beta$-carotene was altered by heavy metals in carrot is unknown and further studies need to be carried out. It is worth mentioning that $\alpha$-carotene is the immediate precursor of lutein, while $\beta$-carotene follows a different 
Table 3. Content of lutein and $\mathrm{IC}_{50}$ values in onion samples $^{a}$.

\begin{tabular}{|c|c|c|}
\hline & $\begin{array}{c}\text { Lutein concentration } \\
\left(\mathrm{mg} \cdot \mathrm{kg}^{-1} \text { edible portion) }\right.\end{array}$ & $\begin{array}{c}\mathrm{IC}_{50}\left(\mathrm{mg}_{\text {solution }} \mathrm{ml}^{-1} \text { sample }\right. \\
\text { solution }\end{array}$ \\
\hline \multicolumn{3}{|l|}{ Asopos samples } \\
\hline $\mathrm{S}_{1}$ & $27.98 \pm 2.51$ & $3.38 \pm 0.169$ \\
\hline $\mathrm{S}_{2}$ & $7.93 \pm 0.83$ & $2.68 \pm 0.134$ \\
\hline $\mathrm{S}_{3}$ & $23.41 \pm 2.59$ & $1.97 \pm 0.099$ \\
\hline $\mathrm{S}_{4}$ & $8.39 \pm 1.77$ & $2.67 \pm 0.134$ \\
\hline $\mathrm{S}_{5}$ & $28.13 \pm 3.15$ & $1.78 \pm 0.089$ \\
\hline $\mathrm{S}_{6}$ & $8.75 \pm 1.65$ & $2.39 \pm 0.120$ \\
\hline $\mathrm{S}_{7}$ & $48.96 \pm 1.84$ & $2.35 \pm 0.118$ \\
\hline $\mathrm{S}_{8}$ & $33.50 \pm 1.27$ & $2.16 \pm 0.108$ \\
\hline Mean & $23.38 \pm 1.95$ & $2.42 \pm 0.121$ \\
\hline \multicolumn{3}{|l|}{ Control samples } \\
\hline $\mathrm{C}_{1}$ & $29.43 \pm 2.40$ & $2.83 \pm 0.142$ \\
\hline $\mathrm{C}_{2}$ & $16.91 \pm 2.71$ & $2.41 \pm 0.121$ \\
\hline $\mathrm{C}_{3}$ & $10.54 \pm 0.62$ & $3.25 \pm 0.163$ \\
\hline Mean & $18.96 \pm 1.91$ & $2.83 \pm 0.142$ \\
\hline$p$ values (F-Test) & 0.68 & 0.95 \\
\hline$p$ values (T-Test) & 0.64 & 0.24 \\
\hline
\end{tabular}

${ }^{\alpha}$ Each value is the mean of three replicates \pm standard deviation (95\% confidence levels).

biosynthetic pathway. For the biosynthesis of lutein from $\alpha$-carotene, the enzymes CRTL-e (e-ring hydroxylase) and CRTL-b (b-ring hydroxylase) are involved which are ferredoxins and require iron as co-factor [22]. Nickel can possibly substitute iron, affecting their metabolic function in potato tubers [19]. A probable explanation for the decrease of lutein in Asopos potatoes could be the substitution of iron by nickel in these enzymes and the consequential inhibition of their activities. In our previous work [5] the levels of nickel in Asopos potatoes were found $800 \pm 961 \mu \mathrm{g} \cdot \mathrm{kg}^{-1}$ wet weight as opposed to $78 \pm$ $14 \mu \mathrm{g} \cdot \mathrm{kg}^{-1}$ wet weight in control samples.

\subsection{DPPH Radical Scavenging Activity Analysis}

DPPH radical scavenging activity was quantified in terms of percentage inhibition of a pre-formed free radical by antioxidants in each sample. There was no significant difference in the $\mathrm{IC}_{50}$ levels in Asopos and control samples for all three cultivars examined as the F-test data suggest. Potato tubers exhibited the highest antioxidant capacity among carrots and onions, with the latter two cultivars presenting similar scavenging activity. Asopos carrots showed no statistically significant difference to control ones $(p=0.63)$ (Table 1). Statistical analysis showed similar results for both potatoes and onions, $(p=$ $0.59)$ and $(p=0.24)$ respectively (Tables $2-3)$.

These negative results on the differentiation of DPPH scavenging activity between Asopos and control samples of all three cultivars could be explained on the basis that plants have the ability to develop several defensive mechanisms in order to face toxicity due to high uptake of heavy metals. In consequence, it is possible that the examined tubers have increased the production of other antioxidant substances to offset the decrease of carotenoids. Furthermore, the results of each antioxidant capacity assay reflect the specific reaction which takes place and the specific conditions in which it is conducted [23]. Thus, it is possible that the DPPH could not show any differences.

\section{Conclusions}

Our previous research on food originating from Asopos region [5] has shown that the pollution of the river and of the underground water bed can cross-contaminate the food chain with $\mathrm{Ni}$ and $\mathrm{Cr}$, since samples of food tubers (carrots, onions and potatoes) grown in Asopos area were found to have considerable higher levels of $\mathrm{Ni}$ and $\mathrm{Cr}$ as opposed to other unpolluted samples areas. This being the first indication that the polluted water bed of the region may have a considerable impact on the food chain. The question was then posed as to if this heavy metal uptake by the plants affects their secondary metabolism. An answer portrayed by the data reported in this paper suggests that $\mathrm{Ni}$ and $\mathrm{Cr}$ affect the levels of carotenoids and antioxidant activity in the food cultivars examined. Specifically, uptake of $\mathrm{Ni}$ and $\mathrm{Cr}$ by the plant results in reduced levels of carotenoids.

To conclude, not only do these Asopos samples contain increased levels of heavy metals which have a detrimental effect (possibly toxic) to human health but also a reduction in the levels of carotenoids, which further reduces the supposed nutritional value and benefits of these foods. These foods are basic staple foods which also constitute a major part of infants' dietary intake so particular attention should be paid when evaluating their nutritional value. Future studies on the impact of pollution on food quality and safety should focus not only on the levels of trace elements in food but also evaluate the biosynthesis of secondary metabolites in these food tubers (e.g. carotenoids, as studied in this paper). Our current research efforts are now focusing on these three cultivars which are being irrigated with water containing certain levels of $\mathrm{Ni}$ and $\mathrm{Cr}$ under controlled greenhouse 
conditions with the aim to further quantify the impact of these heavy metals on the secondary metabolism.

\section{REFERENCES}

[1] R. K. Sharma, M. Agrawal and F. M. Marshall, "Heavy Metals in Vegetables Collected from Production and Market Sites of a Tropical Urban Area of India," Food and Chemical Toxicology, Vol. 47, No. 3, 2009, pp. 583591. doi:10.1016/j.fct.2008.12.016

[2] D. Uprety, M. Hejcman, J. Száková, E. Kunzová and P. Tlustoš, "Concentration of Trace Elements in Arable Soil after Long-Term Application of Organic and Inorganic Fertilizers," Nutrient Cycling in Agroechosystems, Vol. 85, No. 3, 2009, pp. 241-252. doi:10.1007/s10705-009-9263-x

[3] B. Song, M. Lei, T. Chen, Y. Zheng, Y. Xie, X. Li and D. Gao, "Assessing the Health Risk of Heavy Metals in Vegetables to the General Population in Beijing, China," Journal of Environmental Science, Vol. 21, No. 12, 2009, pp. 1702-1709. doi:10.1016/S1001-0742(08)62476-6

[4] EFSA: Panel on Contaminants in the Food Chain (CONTAM), "Cadmium in Food," 2009. http://www.efsa.europa.eu/en/efsajournal/pub/980.htm

[5] C. G. Kirkillis, I. N. Pasias, S. Miniadis-Meimaroglou, N. S. Thomaidis and I. Zabetakis, "Concentration Levels of Trace Elements in Carrots, Onions and Potatoes Cultivated in Asopos Region, Central Greece," Analytical Letters (in press).

[6] A. K. Shanker, C. Cervantes, H. Loza-Tavera and S. Avudainayagam, "Chromium Toxicity in Plants," Environment International, Vol. 31, No. 5, 2005, pp. 739-753. doi:10.1016/j.envint.2005.02.003

[7] P. A. Biacs, H. G. Daood and I. Kadar, "Effect of Mo, Se, $\mathrm{Zn}$, and $\mathrm{Cr}$ Treatments on the Yield, Element Concentration, and Carotenoid Content of Carrot," Journal of Agricultural and Food Chemistry, Vol. 43, No. 3, 1995, pp. 589-591. doi:10.1021/jf00051a007

[8] K. H. Cheeseman and T. F. Slater, "An Introduction to Free Radical Biochemistry," British Medical Bulletin, Vol. 49, No. 3, 1993, pp. 481-493.

[9] M. M. Calvo, "Lutein: A Valuable Ingredient of Fruit and Vegetables," Critical Reviews in Food Science and Nutrition, Vol. 45, No. 7, 2005, pp. 671-696. doi:10.1080/10408690590957034

[10] P. M. Bramley, "Is Lycopene Beneficial to Human Health?" Phytochemistry, Vol. 54, No. 3, 2000, pp. 233236. doi:10.1016/S0031-9422(00)00103-5

[11] D. A. Cooper, A. L. Eldridge and J. C. Peters, "Dietary Carotenoids and Certain Cancers, Heart Disease, and AgeRelated Macular Degeneration: A Review of Recent Research," Nutrition Reviews, Vol. 57, No. 7, 1999, pp. 201214.

[12] J. Clotault, D. Peltier, R. Berruyer, M. Thomas, M. Briard and E. Geoffriau, "Expression of Carotenoid Biosynthesis Genes during Carrot Root Development," Journal of Experimental Botany, Vol. 59, No. 13, 2008, pp. 3563-3573. doi:10.1093/jxb/ern210

[13] P. D. Fraser and P. M. Bramley, "The Biosynthesis and Nutritional Uses of Carotenoids," Progress Lipid Research, Vol. 43, No. 3, 2004, pp. 228-265. doi:10.1016/i.plipres.2003.10.002

[14] H. Clijsters, A. Cuypers and J. Vangronsveld, "Physiological Responses to Heavy Metals in Higher Plants; Defence against Oxidative Stress," Zeitschrift fur Naturforschung-A Journal of Biosciences, Vol. 54, No. 9-10, 1999, pp. 730-734.

[15] R. E. Wrolstad, E. A. Decker, S. J. Schwartz and P. Sporns, "Chromatographic Techniques for Carotenoid Separation," In: N. E. Craft, Ed., Handbook of Food Analytical Chemistry, John Willey \& Sons, Inc., Hoboken, 2005, pp. 91-97.

[16] H. Muller, "Determination of the Carotenoid Content in Selected Vegetables and Fruit by HPLC and Photodiode Array Detection," Zeitschrift für Lebensmitteluntersuchung und-Forschung A, Vol. 204, No. 2, 1997, pp. 88-94. doi:10.1007/s002170050042

[17] P. Molyneux, "The Use of the Stable Free Radical Diphenylpicryl-Hydrazyl (DPPH) for Estimating Antioxidant Activity," Songklanakarin Journal of Science and Technology, Vol. 26, No. 2, 2004, pp. 211-219.

[18] D. Liu and I. Kottke, "Subcellular Localization of Chromium and Nickel in Root Cells of Allium Cepa by EELS and ESI," Cell Biology and Toxicology, Vol. 19, No. 5, 2003, pp. 299-311. doi:10.1023/B:CBTO.0000004984.87619.15

[19] R. Shukla and R. Gopal, "Excess Nickel Alters Growth, Metabolism and Translocation of Certain Nutrients in Potato," Journal of Plant Nutrition, Vol. 32, No. 6, 2006, pp. 1005-1014. doi:10.1080/01904160902872800

[20] R. K. Sharma, M. Agrawal and S. B. Agrawal, "Physiological and Biochemical Responses Resulting from Cadmium and Zinc Accumulation in Carrot Plants," Journal of Plant Nutrition, Vol. 33, No. 7, 2010, pp. 1066-1079. doi:10.1080/01904161003729774

[21] S. Samantaray, G. R. Rout and P. Das, "Role of Chromium on Plant Growth and Metabolism," Acta Physiologiae Plantarum, Vol. 20, No. 2, 1998, pp. 201-212. doi:10.1007/s11738-998-0015-3

[22] S. Römer and P. D. Fraser, "Recent Advances in Carotenoid Biosynthesis, Regulation and Manipulation," Planta, Vol. 221, 2005, pp. 305-308. doi:10.1007/s00425-005-1533-5

[23] L. M. Magalhaes, M. A. Segundo, S. Reis and J. L. F. C. Lima, "Methodological Aspects about in Vitro Evaluation of Antioxidant Properties," Analytica Chimica Acta, Vol. 613, No. 1, 2008, pp. 1-19. doi:10.1016/j.aca.2008.02.047 